\title{
Resenha: Análise de Cargo, Recrutamento e Seleção: Manual Prático para Aumentar a Eficácia na Contratação de Profissionais
}

\author{
Jéssika Marcolino Silva* \\ Universidade Federal de Goiás, Jataí, GO, Brasil \\ André Amaral Bravin \\ Universidade Federal de Jataí, Jataí, GO, Brasil
}

\section{Book Review: Job Analysis, Recruitment and Selection: Practitioner Guide to Increase Professional Hiring Effectiveness}

\begin{abstract}
Gusso, H. L. (2015). Análise de Cargo, recrutamento e seleção: Manual prático para aumentar a eficácia na contratação de profissionais. Curitiba: N1 Tecnologia Comportamental.
\end{abstract}

A Análise do Comportamento nas Organizações (Organizational Behavior Management [OBM]) é a aplicação da Análise do Comportamento ao contexto organizacional. O ponto de partida da OBM foram as obras de Watson e Skinner, mas desde 1977, o Journal of Organizational Behavior Management (JOBM) é o principal fórum de discussão científica internacional da área (http://www. obmnetwork.com). No Brasil o campo ainda é pouco conhecido, mas conta com o "Grupo Especial de Interesse em Análise do Comportamento nas Organizações" vinculado à ABPMC (Associação Brasileira de Psicologia e Medicina Comportamental) (https://obmbrasil.wordpress.com), que busca a divulgação e consolidação da área no país, agregando traduções e publicações, bem como reunindo os profissionais brasileiros que atuam sob esse enfoque. A exemplo, em 2015, o grupo organizou o I Encontro Brasileiro de Análise do Comportamento nas Organizações (http://n1tc.com.br/obm). O cerne dessa resenha é justamente uma nova publicação lançada por um dos membros desse Grupo Especial de Interesse.

Recentemente o Prof. Dr. Helder Lima Gusso ${ }^{1}$ lançou o livro Análise de Cargo, Recrutamento e Seleção, um manual didático voltado para qualificar estudantes de psicologia, psicólogos ou pessoas que lidam com essas funções. Sua escrita baseou-se na observação comportamental de ações necessárias para a realização de um processo de seleção visando o preenchimento de vagas em uma organização (Gusso, 2015). O material foi elaborado ao longo de 10 anos,

* Endereço para correspondência: Universidade Federal de Jataí, Rodovia BR 364, Km 1972, n 3.800, Parque Industrial, Jataí, GO, Brasil. CEP, 75.801-615.

E-mail: jessikaufg@hotmail.com; andrebravin@yahoo.com

1 Graduado em Psicologia (UFPR - 2005), especialista em Administração (FAE Business School - 2005), Mestre e Doutor em Psicologia (UFSC - 2008 e 2013, respectivamente). É analista do comportamento acreditado pela ABPMC (2015), e membro da Organizational Behavior Management Network (desde 2006). Atualmente leciona no curso de Psicologia da UFSC. quando o autor foi convidado a aperfeiçoar o processo de seleção de uma organização. O mesmo foi retomado para facilitar a aprendizagem de universitários que apresentavam insatisfações e/ou dificuldades na área. Durante o processo de qualificação do material, quatro estagiárias colaboraram para levar o projeto a um novo patamar, com pesquisas teóricas que possibilitaram a descoberta de 30 comportamentos básicos necessários para a realização das funções de analisar cargo, recrutar e selecionar pessoas.

A obra organiza-se baseada em três processos sequenciais de atividades do psicólogo organizacional: análise de cargo, recrutamento e seleção. Cada um desses processos/ capítulos é decomposto em 10 etapas menores, sequenciais e interdependentes, que ao final culminam com a sua realização. A ênfase do texto está no primeiro processo, considerada pré-requisito para os demais, e um dos méritos do texto é dar a devida importância ao detalhamento deste. $\mathrm{Na}$ sessão inicial o autor defende que os três processos abordados no livro, em última instância, são um sistema comportamental. O autor defende ainda que esses três processos, embora sejam independentes um do outro, não têm sido considerados como inter-relacionados e sequenciais. Isto é, para se realizar uma seleção com qualidade, seria fundamental realizar previamente uma boa análise de cargo, e em seguida, um bom recrutamento. Esse olhar traria, segundo o autor, uma mudança da ênfase de resolução de problemas, para a produção de resultados significativos e duradouros na organização (principal marco da OBM).

Quanto à análise de cargo, são expostas duas situações em que ela é empregada: a gerência de desempenho humano, e a contratação profissional para se ocupar um posto na organização. Essa sessão foca os componentes do comportamento de analisar cargos, exemplificando e nomeando situações com a qual o analista irá lidar (antecedentes), as ações necessárias (comportamentos) e as consequências que devem ser produzidas (consequentes). No que tange às ações necessárias, essas são divididas em 10 etapas sequenciais e elementares do processo. A definição dessas etapas e sua sequência, segundo Gusso (2015), foi 
balizada na revisão de 25 estudos, e testada empiricamente de diferentes maneiras em sua prática profissional. Assim, a sequência apresentada foi a que produziu melhores resultados em menor tempo: analisar o histórico do cargo na empresa, analisar características do cargo no mercado de trabalho, caracterizar as situações com as quais o trabalhador terá que lidar, caracterizar os resultados que o trabalhador deverá produzir, caracterizar as ações a serem apresentadas, organizar as informações em um sistema comportamental, completar a análise dos comportamentos, nomear e hierarquizar os comportamentos identificados, caracterizar outros requisitos da vaga e caracterizar as condições que a empresa dispõe ao cargo.

O recrutamento é o momento no qual o analista visa identificar no mercado de trabalho, profissionais com as características necessárias para ocupar o cargo (daí sua relação com a etapa anterior). Tal qual na sessão anterior, esta foi dividida em 10 etapas, a saber: identificar se há profissionais qualificados dentro da organização, avaliar benefícios de fazer recrutamento interno, externo ou misto, avaliar cenário atual do mercado de trabalho relacionado ao cargo, definir melhores locais e meios para divulgação da vaga, decidir o que divulgar sobre a vaga e a empresa, decidir duração da divulgação da vaga, diagramar material de divulgação, divulgar vaga, triar candidatos, avaliar resultados do processo e propor aperfeiçoamentos.

Por fim, a seleção, que tem o objetivo de classificar os candidatos e escolher os mais adequados ao cargo. As 10 etapas discutidas nessa sessão são: identificar os comportamentos e demais características que precisam ser avaliados, identificar as variáveis a serem observadas direta ou indiretamente, selecionar ou desenvolver instrumentos e procedimentos para avaliação, programar o processo seletivo, calcular os custos do processo seletivo, coletar dados dos candidatos, analisar dados coletados de cada candidato, comparar dados dos candidatos com o perfil do cargo, hierarquizar candidatos aptos e comunicar decisão aos candidatos.

Ao longo de todas as três sessões do livro, o leitor se depara com conteúdo deliberadamente escolhido para tentar instalar o repertório (as ações necessárias/comportamento/ etapas dos processos) no leitor/analista interessado. Dentre esses conteúdos, existe instrução formal (e.g., questões para verificação de aprendizagem; exercícios de fixação), ensaio comportamental (e.g., tarefas idênticas às que o analista fará em situação natural como criação de protocolos) e modelos auxiliares (e.g., modelos de questionários, registros de dados e documentos).

Notoriamente o livro de Gusso (2015) apresenta uma ênfase no processo de análise de cargo, comparativamente aos processos de recrutamento e seleção. E o que é apresentado como um diferencial na primeira fração do livro (o detalhamento do processo de análise de cargo) é um ponto crítico nas outras duas frações. Isto é, recrutamento e seleção não receberam a mesma atenção que a sessão anterior. A possibilidade de aprofundamento e ampliação da questão que o leitor tem na primeira sessão não ocorre nas seguintes, e ambas sessões poderiam se beneficiar de uma revisão que ampliasse a discussão com o acréscimo de referências bibliográficas e ferramentas (modelos auxiliares), viabilizando ao interessado o aprofundamento no tema. Ainda no quesito referências, a escassez de material bibliográfico para algumas afirmações do autor é percebida, como quando o autor afirma "embasado em centenas de pesquisas já realizadas no Brasil e no mundo" (p. 15), mas lista somente uma fonte; ou quando relata ter realizado uma revisão de 25 estudos, embora os mesmos não tenham sido citados ou relatados ao longo do escrito. A complementação da leitura de Gusso (2015) com outras leituras da área de Psicologia Organizacional e do Trabalho, como o Dicionário de Psicologia do Trabalho e das Organizações (Bendasolli \& Borges-Andrade, 2015), certamente beneficiará o interessado pelo tema.

Ao mesmo tempo o leitor deve compreender que o livro possui mais uma "razão instrumental" do que propriamente uma "razão teórica". Não se trata de uma obra destinada a discussão teórica exaustiva sobre os temas propostos, não visa contemplar todas as funções do psicólogo organizacional (e.g., nada é discutido sobre treinamento e avaliação de desempenho), nem tampouco é um compêndio de OBM no Brasil. Outrossim o livro auxilia o leitor/analista interessado, com um exemplo bem-sucedido de uma intervenção prática (para as funções de análise de cargo, recrutamento e seleção), favorecendo o conhecimento das habilidades e competências necessárias para a execução de uma boa prática profissional, dando a oportunidade para o que mesmo inicie o treinamento com a leitura do livro.

Um ponto é justamente sobre o público ao qual o livro se dirige, se ao analista de Recursos Humanos (RH) que desconhece as práticas da OBM, ou analista do comportamento que se interessa pelo campo organizacional, e a conclusão a qual chegamos, é que ambos se beneficiam com a obra. O livro foca a dimensão comportamental do leitor (seja ele analista de RH ou do comportamento), explicitando os comportamentos desejáveis para uma boa prática profissional. Nesse sentido, a construção do livro toma como preceito que cada uma de suas sessões são classes de respostas ("analisar cargo"; "recrutar" e "selecionar"), organizada em 10 comportamentos encadeados, cujas consequências são os resultados esperados para cada um desses processos (i.e., a descrição do cargo, os candidatos da seleção, a ocupação da vaga).

Outro diferencial do escrito é que o mesmo apresenta uma estrutura didática inspirada na Instrução Programada de Ensino (PSI), ou seja, as características de uma boa prática educacional (i.e., objetivos finais previamente estabelecidos, o curso dividido em pequenas unidades com grau de dificuldade crescente, o domínio sequencial do conteúdo/ proficiência, o ritmo de estudo depende do aluno e a ênfase no material escrito) (Keller, 1968), o que corrobora o intuito didático da obra.

Assim, compreendemos que o livro Análise de Cargo, Recrutamento e Seleção: Manual prático para aumentar a eficácia na contratação de profissionais (Gusso, 2015), é uma boa adição ao arsenal bibliográfico do psicólogo no Brasil, e se tornará uma importante ferramenta em revisões posteriores, sobretudo se o autor ampliar o escopo do texto para outras práticas do campo organizacional, como o treinamento, desenvolvimento e avaliação de desempenho. A sagacidade em tratar o tema tomando como alicerce a análise 
do comportamento do analista de RH e, a partir daí, realizar análises funcionais dos repertórios que deveriam ser emitidos para a execução de uma boa prática, é o principal diferencial na abordagem deste manual comparativamente aos outros da área. O resgate de princípios do PSI para a organização lógica do conteúdo é outro diferencial que faz da leitura do texto de Gusso (2015) ser uma leitura ativa e pedagógica.

\section{Referências}

Gusso, H. L. (2015). Análise de cargo, recrutamento e seleção: Manual prático para aumentar a eficácia na contratação de profissionais. Curitiba: N1 Tecnologia Comportamental.
Bendasolli, P. F., \& Borges-Andrade, J. E. (2015). Dicionário de psicologia do trabalho e das organizações. São Paulo: Casa do Psicólogo.

Keller, F. S. (1968). "Good-bye, Teacher...”. Journal of Applied Behavior Analysis, 1(1), 79-89. 